\title{
Trazando rutas de la migración de tránsito irregular o no documentada por México
}

\section{Graciela Martínez, ${ }^{*}$ Salvador David Cobo, ${ }^{* *}$ Juan Carlos Narváez ${ }^{* * *}$}

\author{
Perfiles Latinoamericanos | Artículo \\ vol. 23 | núm. 45 | 2015 \\ pp. $127-155$
}

\begin{abstract}
Resumen
En el presente artículo se analizan los cambios y las continuidades en las rutas del flujo de migración de tránsito irregular o no documentada por México. Con base en los registros administrativos del Instituto Nacional de Migración relacionados con los eventos de retención de migrantes que no acreditan su legal estancia en el país, se delinean las posibles rutas de internación, recorrido y salida de la migración centroamericana que se dirige a Estados Unidos. Los resultados advierten sobre la complejidad que ha adquirido este fenómeno como consecuencia de factores asociados a la seguridad, los fenómenos naturales, la violencia y las políticas migratorias en Estados Unidos y México.
\end{abstract}

\begin{abstract}
The purposes of this article are plotted and analyzed changes and continuities in the flow paths of migration of undocumented transit spanning through Mexico. Records-based store administration of Instituto Nacional de Migración related events of retention of migrants that not accredit his legal stay in Mexico and through geographical and descriptive analytical method would outline possible routes of admission, tour and flow of undocumented Central American migrants that are directed toward the United States. Results warn about the complexity that it has acquired this migratory phenomenon as a result of factors associated with security, natural phenomena, violence and immigration policies in the United States and Mexico.
\end{abstract}

Palabras clave: migración de tránsito irregular o no documentada, registros administrativos, eventos de retención de migrantes, rutas del flujo de tránsito, rutas de internación, recorrido y salida, migrantes centroamericanos.

Keywords: undocumented or irregular transit migration, migration routes, migration regions, administrative records, retained events, Central American migrants.

* Doctora en Geografía por la Universidad Nacional Autónoma de México. Directora de Estadística del Centro de Estudios Migratorios de la Unidad de Política Migratoria de la Secretaría de Gobernación.

** Candidato a doctor en Estudios de Población por El Colegio de México. Profesor de la Escuela Superior de Economía del Instituto Politécnico Nacional e investigador del Centro de Estudios Migratorios de la Unidad de Política Migratoria de la Secretaría de Gobernación.

*** Candidato a doctor en Ciencias Sociales por la Facultad Latinoamericana de Ciencias Sociales, Sede México. Investigador del Centro de Estudios Migratorios de la Unidad de Política Migratoria de la Secretaría de Gobernación. 


\section{Introducción ${ }^{1}$}

E

mundo globalizado, caracterizado por el comercio de mercancías y el intercambio no restringido de capitales financieros, encuentra una de sus mayores contradicciones en la libertad de movimiento de la fuerza de trabajo. El modelo económico contemporáneo se distingue también por el tránsito de personas que, en busca de mejores condiciones de vida, se desplazan a lugares distintos de su lugar de nacimiento.

En este sentido, tratando de alcanzar el llamado "sueño americano", grupos de centroamericanos ingresan a territorio mexicano por áreas inhóspitas e inseguras de la frontera sur, con el propósito de continuar su travesía hacia el norte. Así, el territorio mexicano se ha convertido en una antesala física para materializar sus objetivos personales y familiares. El tránsito irregular de migrantes inicia comúnmente en algún punto del sur de México (puerta de entrada) y termina en su frontera norte compartida con Estados Unidos (puerta de salida).

Desde la década de 1980, México es uno de los principales países de migración de tránsito no documentada en América Latina, cuyos detonantes habrían sido, entre otros, las guerras civiles, los conflictos políticos y los cambios económicos estructurales que tuvieron lugar en Centroamérica. ${ }^{2}$ Para épocas actuales, a la par de la diversificación de los flujos migratorios de tránsito, han proliferado diversas amenazas para la integridad de los propios migrantes durante su travesía por México. Los migrantes están inmersos en una constante vulnerabilidad durante su paso por regiones y zonas específicas del país.

En contextos de transformaciones en la dinámica y de mayor vulnerabilidad en la que se desarrolla la migración de tránsito, se pretende un análisis descriptivo, desde un enfoque geográfico, que muestre los cambios y las continuidades en las rutas de los flujos migratorios de tránsito no documentado

1 Una versión previa del artículo se presentó en el 3er. Congreso Nacional de Ciencias Sociales, desarrollado del 26 de febrero al 1 de marzo de 2012 en la Ciudad de México. Se agradecen los comentarios del moderador de la sesión, Hugo Ángeles Cruz. Los errores son responsabilidad de los autores, cuyas opiniones aquí vertidas no necesariamente reflejan las visiones de las instituciones a las que están adscritos. Los autores están en deuda con los comentarios y las observaciones de dos dictaminadores anónimos.

2 En el flujo migratorio actual de tránsito no documentado participan migrantes procedentes de la región centroamericana, de otros países de Latinoamérica y de regiones extracontinentales, principalmente de África y Asia, aunque su participación, de acuerdo con reportes periodísticos y estadísticas migratorias disponibles, es aún reciente. 
que utilizan a México para llegar a Estados Unidos. ${ }^{3}$ Para ello, se emplean los registros administrativos del Instituto Nacional de Migración (INM), relacionados con los eventos de retención de migrantes que no acreditan su legal estancia en México. ${ }^{4}$

\section{Contexto de la migración de tránsito y de sus rutas por México}

Las condiciones actuales en las que se desarrolla la migración no documentada de tránsito por México, tanto de orden estructural como coyuntural, dotan de elementos para redefinir o repensar esta dinámica como de "migración de tránsito paso a paso", y no sólo como un estadio intermedio entre el origen y el destino migratorio (Bade, 2000, citado por Düvel, 2006).

Entre los elementos que perfilan el carácter contemporáneo de la migración de tránsito destacan: a) el mayor control migratorio — desde la frontera sur y a lo largo de la ruta histórica de tránsito no documentado hacia la frontera norte- por parte del gobierno mexicano o lo que se ha llamado "la frontera vertical"; b) la fractura de la red de transporte ferroviaria como consecuencia de los fenómenos y desastres naturales; c) el reforzamiento de las medidas de seguridad implementadas en la frontera sur y al interior de los Estados Unidos; d) la incorporación del crimen organizado y el encarecimiento de la "industria del tráfico de personas"; e) el incremento del riesgo en la trayectoria migratoria, y f) la situación de violencia generalizada en México traducida en mayor robo, extorsión y secuestro hacia migrantes (Casillas, 2010; Anguiano, y Corona, 2009; Castillo, 2008; Pérez, 2008). En el abordaje de la migración de tránsito no documentada por México, sucede con frecuencia que se la asocia a la que ocurre sólo en la región de su frontera sur, en la cual se agrupan dimensiones diferentes del fenómeno, mismas, que, como conjunto, tienen coherencia analítica debido a la condición y posición geográfica compartida. ${ }^{5}$

3 Para los fines del artículo, por "migración irregular o no documentada de tránsito por México" se entenderá el flujo compuesto por "centroamericanos —nacionales de Guatemala, El Salvador, Honduras y Nicaragua - que se dirigen sin documentos que acrediten legal estancia o les permitan trasladarse hacia Estados Unidos, utilizando a México como ruta de paso". Las estadísticas disponibles del Instituto Nacional de Migración apuntan que los migrantes de estas nacionalidades representan aproximadamente 95\% del flujo total de esta migración de tránsito.

4 El inm es la instancia encargada de la aplicación de la política migratoria en México.

5 En el sur de México convergen - particularmente en las zonas cercanas a los puntos fronterizos de Ciudad Hidalgo/Tecún Umán y Talismán/El Carmen— diversos flujos migratorios, entre éstos los de trabajadores fronterizos agrícolas y de servicios, visitantes fronterizos, turistas y migrantes en tránsito no documentados (Ángeles, 2001 y 2003; Rojas, 2003 y 2006; Anguiano, y Corona, 2009). 
Ciertamente, la migración de tránsito no documentada es uno de los flujos que se encuentran instalados en el cuello de botella fronterizo, sin embargo, sus ecos e impactos van mucho más allá de la frontera sur $y$, por lo tanto, requiere de abordajes amplios en cuanto a su dimensión metodológica, y más extensos en cuanto a su dimensión geográfica (Jaúregi, y Ávila, 2009).

Desde distintos acercamientos de investigación sobre el fenómeno, se han diseñado algunas propuestas de clasificación de las etapas de la migración de tránsito no documentada por México, directamente relacionadas con sus motivaciones. Una de ellas, la más sintética o macroestructural, se divide en dos grandes momentos, definidos como 1) de movilidad internacional forzada: durante la década de 1980 y los primeros ańos de los noventa, los conflictos armados y civiles en Centroamérica, el miedo al reclutamiento obligado en las áreas rurales, la violencia indiscriminada y la polarización política, provocaron la primera ola de migración internacional forzada y masiva hacia Estados Unidos; ${ }^{6}$ y 2) de movilidad internacional económica: posterior a la etapa de conflictos armados en Centroamérica, una segunda oleada de migración internacional se caracteriza o tiene como leitmotiv el factor económico ${ }^{7}$ (Narváez, 2007).

La segunda clasificación, quizá la más referida en los reportes de investigación, no contradice la primera propuesta, sino que presenta una clasificación desagregada y exhaustiva. Comprende un periodo que va desde la década de los cuarenta hasta la de los noventa, y se resume en los siguientes cuatro tipos de flujos migratorios:

a) Migraciones y crecimiento urbano: la primera etapa de migración internacional que, se presume, cruzó México en su tránsito hacia el norte, data de los años cuarenta y se extiende hasta la década de los setenta. Se caracteriza por su carácter temporal, estacional y no masivo; y se asocia al crecimiento urbano que, en general, se produjo en las ciudades latinoamericanas, el cual traía consigo movimientos poblacionales al interior de los países y la región (Singer, 1998).

b) Migraciones y conflicto armado: los dos principales motivos para migrar en esta etapa fueron el conflicto armado y la inestabilidad política en Centroamérica. Se puede hablar por primera vez de una migración de carácter masivo y de larga

6 Esta migración se caracterizó en un principio por ser de hombres jóvenes, pero, para mediados de la década de los ochenta y ligado ello a la formación de las primeras redes sociales migratorias en los Estados Unidos, las mujeres se unieron al fenómeno de movilidad internacional forzada.

7 Esto no quiere decir que sea una migración estrictamente laboral, ya que debido a una serie de estrategias de movilidad consolidadas en los lugares de origen y destino, se producen, sumadas a ésta, migraciones guiadas por motivaciones alternas que responden a la reunificación familiar, la descomposición social en zonas del posconflicto y a los desastres naturales. 
permanencia. En un periodo de diez años que comprende de 1980 a 1990, la migración internacional centroamericana hacia Estados Unidos, Canadá y México se consolidó como flujo de tránsito y diáspora, sin embargo, esto no significó que, durante este periodo, el perfil del migrante no sufriera cambios. El migrante centroamericano pasó del desplazamiento forzado (de zonas de conflicto) al refugio; del migrante transfronterizo, al migrante de tránsito no documentado.

c) Migraciones, posconflicto armado y desajuste económico: en los primeros años de la década de los noventa — una vez terminados los conflictos armados, 1992 para El Salvador, y 1996 para Guatemala—, se esperaba un retorno migratorio permanente y voluntario desde Estados Unidos, Canadá y México hacia Centroamérica. Sin embargo, lo que ocurrió con cierta fuerza fueron retornos paulatinos, individuales y obligados (vía la deportación o remoción desde Estados Unidos). Sin una política clara de reinserción para los desplazados por el conflicto armado y en un contexto de desajuste económico, fue difícil para los migrantes retornados incorporarse exitosamente (económica, social, cultural y políticamente) a sus sociedades de origen; $y$, ante la escasez de fuentes de empleo y otras variables, lo que se reactivó fue el circuito migratorio internacional de tránsito no documentado hacia Estados Unidos por México, el cual se conformaba por migrantes noveles (sin experiencia) y migrantes veteranos (experimentados), los cuales, dadas las condiciones de internación y vías de comunicación disponibles usaban la ruta tradicional que iniciaba en Chiapas y culminaba principalmente en los cruces fronterizos hacia Laredo o California en Estados Unidos.

d) Migraciones y desastres naturales: pasada la mitad de la década de los noventa, la región centroamericana fue azotada por el huracán Mitch (1998), lo cual desató una nueva corriente migratoria, que se sumó al ya establecido flujo migratorio de tránsito no documentado motivado por la reunificación familiar, por las condiciones sociales y económicas del posconflicto armado, por la búsqueda de nuevas fuentes de empleo, y, en general, por la oportunidad de obtener mejor calidad de vida para los propios migrantes y sus familias. Se estima que, entre 1997 y 1999, el volumen del flujo migratorio de tránsito no documentado por México pasó de 176 mil a 274 mil eventos, es decir, que se presentaron 98 mil eventos más, independientemente del carácter de la migración: circular, temporal, permanente o transnacional (Rodríguez et al., 2011; Narváez et al., 2011; Castillo, 2008; Casillas, 2007).

Ahora bien, a partir del año 2000, se puede hablar del inicio de una nueva etapa para la migración de tránsito no documentada, la cual se podría denominar 
migración de tránsito y complejidad. Esta etapa, de acuerdo con su carácter heterogéneo, se subclasifica a partir de los siguientes puntos de coyuntura: a) securitización de fronteras y vinculos transnacionales (2001); b) fenómenos climáticos y pandillas (2005); c) crisis económica e incursión del crimen organizado (2008); y d) visibilidad de la violencia (2010). El diseño de estas cohortes temporales responde a la necesidad de observar patrones diferenciados a lo largo del periodo, mismos que no son excluyentes y que, por el contrario, se suman a la complejidad del fenómeno.

\section{a) Securitización de fronteras y vinculos transnacionales (2001).}

Los ataques terroristas del 09/11 de 2001 marcaron una nueva era para las políticas migratorias globales. Después de la caída de las Torres Gemelas en Nueva York, vino no sólo un cambio en el discurso y el trato del tema de la inmigración en Estados Unidos, sino una transformación orgánica en los aparatos institucionales que atendían el tema migratorio. Desaparece el Immigration and Naturalization Service (INS) y se funda el Department of Homeland Security (DHS) que concentra, entre otras áreas, al Immigration and Customs Enforcement (ICE), al Customs and Border Protection (Свр) y al U.S. Citizenship and Immigration Services (uscis). Dicha reestructuración se ubica en el eje de "migración y seguridad nacional", mismo sobre el que se sustenta gran parte del desarrollo de las políticas migratorias de inicios del siglo xxi. Para el caso de la migración de tránsito no documentada por México, las medidas de reforzamiento de las fronteras tuvieron una implicación directa para el migrante en los costos del viaje y el cruce. Si bien es cierto que la fuerte inversión de capital económico y humano en la frontera sur de Estados Unidos —alrededor de 30 mil agentes a lo largo de los 3099 kilómetros de frontera con México - no han detenido totalmente los cruces no documentados hacia esa nación, sí han obligado a profesionalizar los servicios de polleros o coyotaje, ${ }^{8}$ y usar métodos más sofisticados para lograr con éxito el tráfico de personas.

En síntesis, la política de securitización y control de las fronteras ha propiciado una migración con mayores costos económicos que fomenta, paradójicamente, vínculos más estrechos entre el crimen organizado y el migrante (crimmigration), y una industria ilícita de la migración (Benítez, 2011; Stumpf, 2006).

\section{b) Fenómenos naturales y pandillas (2005).}

Los costos para el cruce no documentado desde Centroamérica hasta los Estados Unidos atravesando México han sufrido incrementos en sus precios

8 De acuerdo con la clasificación de Kauffer (2003), existían hasta ese año: el pollero migrante, el pollero campesino, el pollero estafeta, y el pollero sin fronteras o profesional. 
desde 2001; los servicios de coyotaje se han elevado a más del cien por ciento. Sin embargo, esto no impactó directamente en el volumen del flujo de manera inmediata. Según estimaciones del flujo migratorio de tránsito no documentado por México, en 2005 se registraron 433 mil eventos de migración de tránsito, llegando así a su límite superior histórico. En octubre de ese mismo año, la región centroamericana y algunos estados del sur de la República Mexicana fueron afectados por el huracán Stan. En Tapachula, Chiapas, como consecuencia de las lluvias y los desbordamientos de ríos, gran parte de la infraestructura de servicios y comunicaciones fueron dañados, entre estos, algunos puentes, carreteras y otras vías de comunicación como la red de transporte ferroviario. La fractura de las vías del tren en Tapachula trajo consigo un desvío o corrimiento (obligado) de la "ruta tradicional de paso por Chiapas" hacia otras conexiones ferroviarias en Tabasco, lo cual significó un cambio de ruta. Se presentaron consecuencias en toda la estructura del curso de tránsito migratorio. Así, al cruzar por caminos y sendas de mayor peligrosidad, se incrementaron los riesgos para los migrantes y los polleros; además, la incursión de otros actores sociales vinculados a actividades ilícitas, como los pandilleros, asaltantes e incluso autoridades de los tres órdenes de gobierno (federal, estatal y municipal), dificultaron más las trayectorias migratorias. Cabe destacar que, a partir de 2006, el flujo migratorio de tránsito por México ha seguido un patrón de desaceleración, pasando, de 333 mil en ese año a 140 mil eventos en 2010 (Rodríguez et al., 2011; Castillo, y Toussaint, 2010).

\section{c) Crisis económica e incursión del crimen organizado (2008).}

La crisis económica desatada en Estados Unidos en 2008, sumada a la incursión del crimen organizado y al encarecimiento de la "industria del tráfico de personas", desalentó la migración centroamericana hacia Estados Unidos. A partir de 2005, cuando se registró un máximo histórico de eventos, y hasta 2008, el volumen de los eventos de migración de tránsito observó una tendencia a la baja que se estabilizó en 172 mil eventos anuales. Sin embargo, este menor volumen del contingente no impactó en las formas en que se desarrollaron las trayectorias de tránsito; es decir, ni menos difícil o visible, ni más fluido o menos riesgoso, por el contrario, la incorporación y suma de nuevos actores como el crimen organizado complicó la ruta de migración de tránsito. Se generaron economías informales e ilícitas, ya no sólo en la entrada y la salida de México, sino a lo largo de todos los puntos de la ruta migratoria que siguen los centroamericanos no documentados. La disposición de elementos que hacen de alto riesgo el curso del tránsito migratorio, sumada a la política de seguridad en las fronteras y los territorios de paso (retenes de verificación migratoria), obligó a los migrantes y a sus redes a modificar sus estrategias (no 
más seguras) para la internación y el cruce del territorio mexicano: una de las estrategias recurrentes fue alternar entre distintos tipos de caminos y transportes terrestres (García, y Tarrío, 2008; Casillas, 2007).

\section{d) Visibilidad de la violencia (2010).}

Hasta mediados de la primera década del siglo Xxi, cuando se tocaba el tema de seguridad para la migración de tránsito, lo que se sabía con certeza era que los principales riesgos para los migrantes y sus familias se presentaban en el cruce de la frontera y las áreas vecinas: los accidentes relacionados con el tren o la carretera, los asaltos a mano armada por parte de la delincuencia, y la extorsión de autoridades locales, eran los más comunes. En los años recientes, la violencia hacia los migrantes dio un giro de 360 grados y la seguridad plena para el migrante se volvió una condición aún menos alcanzable. La intervención de la industria del crimen organizado en las redes — antes domésticas - de tráfico de personas migrantes mediante el control de los caminos por donde se trazan las rutas de la migración no documentada no sólo ha encarecido los costos del traslado y el cruce de la frontera norte de México, sino que ha impuesto, por medio del secuestro y la extorsión — a lo largo de la ruta que atraviesa Chiapas, Tabasco, Veracruz y Tamaulipas, el crimen organizado ha instalado casas de seguridad-, una política del miedo y la violencia. La punta del iceberg que devela la magnitud de lo anterior, fue la masacre de 72 migrantes - secuestrados cuando transitaban hacia Estados Unidos-, cuyos cadáveres se encontraron en un rancho de San Fernando, Tamaulipas, en agosto de 2010 (Herrera-Lasso, y Artola, 2011; Casillas, 2010).

Si bien la migración centroamericana de tránsito por México data de hace más o menos cuatro décadas, es hasta los primeros años del siglo xxI que adquiere visibilidad en las agendas de la sociedad civil, la academia y el gobierno. De ahí que una gran parte de los recursos de información, conocimiento, e incluso políticas vinculadas al tema, se comenzaran a diseñar e implementar hasta entonces, por ejemplo: el Plan Sur, 2001-2003, los programas Antimaras Acero de 2003-2004, la Propuesta de Política Migratoria Integral en la Frontera Sur de 2005, o el Plan México, en 2008.

Históricamente, la frontera de Chiapas ha sido la puerta de entrada y el punto de partida de la ruta de tránsito hacia el norte de México. La ruta tradicional que, desde la década de los ochenta y hasta el año 2000, seguían los migrantes centroamericanos iniciaba en el área de Tecún Umán-Suchiate (ruta de la costa), o en el área de El Carmen-La Mesilla (ruta de la panamericana). De acuerdo a la literatura especializada y a los estudios disponibles, la ruta recurrente era la que se mantenía sobre el eje de las líneas del transporte 
ferroviario, sin embargo, sólo existen datos o registros parciales de ello, de los que una gran mayoría se basan en información periodística (García, y Tarrío, 2008; Anguiano, 2009).

Ruiz (2001), Kauffer (2003) y Casillas $(2007 ; 2010)$ han evidenciado cómo los factores sociales, estructurales, políticos y otros, de manera coyuntural fueron dictando el camino de la migración de tránsito. Básicamente, la década pasada se caracterizó por la dispersión de los migrantes en las rutas (de la selva, fronteriza, del Pacífico, de la Sierra Madre), la diversificación en el uso de transportes terrestres (ferrocarril, autobús de pasajeros, camiones de carga, automóviles particulares o transporte público local), la utilización de vías de comunicación principales, secundarias o periféricas (caminos de extravío), por la consolidación de lugares y espacios estratégicos en los diversos tramos y recorridos, y por la intervención de actores de la delincuencia organizada en las redes de tráfico.

Casillas (2007) sugiere que, a través del análisis de la funcionalidad de las rutas (cortas, largas, seguras, alternativas, mixtas), se ha identificado los encadenamientos que se producen en el curso del tránsito migratorio en sitios clave como las plataformas, puertos de enlace y sitios de paso. ${ }^{9}$

Ahora bien, ¿qué ha sucedido en tiempos recientes con las rutas de la migración de tránsito por México? ¿Cómo ciertos acontecimientos naturales y condiciones sociales, políticas y de orden público han modificado los caminos de los migrantes no documentados en tránsito hacia Estados Unidos? Por ejemplo, podemos apuntar que, hasta 2005, por Chiapas cruzaba el $81 \%$ del flujo de migrantes no documentados de tránsito, en tanto que por Tabasco únicamente se internaba el 16\% (estimaciones a partir del Boletín mensual de estadística, UPM-SEGOB). Para finales de ese año, el huracán Stan causó severos daños a las vías del tren que corrían en el tramo costero del Pacífico desde Tapachula y Ciudad Hidalgo, hasta Arriaga, Chiapas, lo cual derivó en un desplazamiento inicial de los flujos de migrantes no documentados en búsqueda de vías que les permitieran tomar la ruta en tren.

Los registros administrativos de retenidos por el INM sugieren que los migrantes decidían entrar por Tabasco, donde la distancia recorrida entre la frontera y la primera estación del ferrocarril era aproximadamente de $53 \mathrm{~km}$ que, comparados con los $258 \mathrm{~km}$ de distancia entre Ciudad Hidalgo (punto

9 De acuerdo con Casillas (2007), las plataformas son zonas de concentración donde arriban, reagrupan, resguardan y parten los grupos de migrantes; los puertos de enlace o nodos son lugares provistos de rutas alternas desde donde se redireccionan los migrantes, y los sitios de paso son lugares en los que transita el migrante sin detenerse o sólo lo hace de forma breve. En realidad, el trabajo de Casillas — pionero en el trazado de rutas de la migración de tránsito por México- da cuenta de la variedad de rutas (terrestres, áreas y marítimas) utilizadas por los migrantes no documentados.

Perfiles Latinoamericanos | vol. 23, núm. 45, enero-junio de 2015 | Flacso México

G. Martínez, S. D. Cobo, J.C. Narváez | Trazando rutas de la migración de tránsito irregular o no documentada 
fronterizo) y Arriaga (primera estación del tren por la ruta de la costa), resultaba más atractivo, no sólo en términos de tiempo, sino también por la disminución de riesgos. La violencia contra los migrantes en tránsito no documentado ya comenzaba a ser más palpable.

En este contexto, Chiapas ya no era el único lugar para el ingreso de migrantes de tránsito, lo que resultaba de la suspensión de la ruta Tapachula-Arriaga del Chiapas-Mayab, como consecuencia de los estragos del huracán y el cese definitivo de las operaciones en $2007 .{ }^{10}$ Para 2010, sólo 64\% del flujo de migrantes de tránsito ingresaba por algún punto fronterizo de Chiapas, en tanto el 32\% ingresaba por Tabasco (estimaciones a partir del Boletín mensual de estadistica, UPM-SEGOB).

Derivado de estos cambios, Tabasco se colocó en la mirada del migrante no documentado, principalmente porque abordar el tren implicaba un camino más corto que la ruta chiapaneca, en este sentido, las comunidades de El Ceibo y Tenosique se vieron envueltas en este fenómeno. Hasta 2009, los puntos donde se presentaba el mayor número de eventos de retención, además de los arriba mencionados, se encontraban en el tramo Chancalá-Palenque, en Chiapas, sitio donde convergen las vías de comunicación iniciadas en la frontera Tabasco-Guatemala y las que suben desde Frontera Corozal, municipio chiapaneco colindante con Guatemala, para seguir el camino hacia el norte a lo largo de Tabasco y Veracruz.

Ahora bien, el tránsito por la región central (zona metropolitana del Valle de México) se podría decir que se ha mantenido sin modificaciones. Una vez sorteados los diferentes peligros y amenazas en las regiones sur y sureste del país, los migrantes llegan a los alrededores del punto conocido como Lechería, en el Estado de México. Allí se han instalado redes de apoyo para los migrantes; una de las más representativas es la Casa del Migrante San Juan Diego.

Después de algún momento de descanso en algunas de las casas de ayuda para migrantes en el centro del país, ellos continúan su travesía utilizando las rutas ferroviarias. Por la mayor disponibilidad de opciones de transporte, podríamos suponer que también utilizan vías terrestres, como las líneas comerciales de autobuses de pasajeros.

En las regiones centro-norte y norte de México, los migrantes de tránsito vuelven a enfrentar amenazas para su integridad. Según reportes y fuentes

10 Desde octubre de 2005, la red del ferrocarril Chiapas-Mayab se encontraba en reconstrucción debido a los estragos del huracán Stan. Y aunque ya se rehabilitó la casi totalidad de la infraestructura ferroviaria, no se encuentra operando, pues las instalaciones en Tapachula, desde donde el tren iniciará el recorrido, se encuentran inconclusas. 
periodísticas, municipios de San Luis Potosí, Durango, Coahuila, Tamaulipas y Nuevo León se han vuelto lugares de asalto y secuestro. Es ampliamente conocida la escena de secuestro y ejecución de migrantes no documentados, principalmente centroamericanos, ocurrida en San Fernando, Tamaulipas. En muchas de estas zonas, los migrantes de tránsito tienen que utilizar sus mejores habilidades y destrezas para sortear las amenazas del crimen organizado, y los puestos de revisión migratoria por parte del INM. Es posible suponer que, en estas regiones, los migrantes modifican sus modos de transportación y sus rutas de tránsito por el país.

Desde esta lógica de argumentación, suponemos que las rutas de tránsito no son siempre continuas ni mucho menos permanentes, sino que se modifican de modo intermitente. Cierto, la dinámica migratoria de tránsito por México ha mostrado signos de cambios en los últimos años, los cuales pudieran ser consecuencia del endurecimiento de las políticas migratorias - tanto en los lugares de destino como en los de tránsito-, de las características geográficas de los lugares de internación a México, de la provisión de apoyo para el cruce no documentado, y por el contexto de violencia generalizada de muchas de las regiones por donde se da el tránsito de migrantes.

\section{Datos y método}

Esta sección contiene la estrategia metodológica para el trazado de las rutas de tránsito de la población migrante no documentada por México. Se presenta la fuente de información utilizada en la construcción de los trayectos migratorios; se discuten las potencialidades y desventajas de los registros administrativos aquí utilizados, y, finalmente, se resumen los lineamientos de clasificación, sistematización y conformación de regiones para la reconstrucción de las rutas de migración de tránsito.

\section{Registros administrativos y la migración de tránsito por México}

Si bien el país cuenta con una amplia tradición de censos de población y encuestas en hogares que han revisado la ya histórica y dinámica migración de mexicanos hacia Estados Unidos, dichos instrumentos no recogen datos de otros procesos migratorios que involucran a la población extranjera residente y no residente en México. En el caso de los flujos de población no documentada en tránsito por México - principalmente de países centroamericanos que pretenden llegar a Estados Unidos-, es prácticamente imposible conocer 
sus patrones y rutas migratorias a través de encuestas en hogares y los censos disponibles.

Pese que es un tema bajo la lupa de la opinión pública, aún se apuntan escasos referentes empíricos de la población en tránsito y de sus problemáticas en los lugares de cruce. Dada la naturaleza del fenómeno (no documentado y clandestino), ${ }^{11}$ la elaboración de metodologías basadas en la aplicación de un instrumento de captación de información directa a los migrantes de tránsito es prácticamente nula. Este escenario, junto con otros, son los principales limitantes para obtener información periódica y de calidad.

Los migrantes en tránsito buscan su invisibilidad para no ser retenidos por las autoridades migratorias y con ello evitar el procedimiento administrativo de devolución a su país de origen. Por tratarse de una población caracterizada por su alta movilidad, que se traslada de un lugar a otro — sin tener un punto fijo de referencia_-, la metodología y las técnicas de muestreo utilizadas en encuestas en hogares - aplicación de cuestionarios a individuos en sus viviendas — quedan rebasadas por el dinamismo de los migrantes de tránsito. ${ }^{12}$ Así, las fuentes de información indirecta aportan conocimientos y elementos complementarios que, en muchas ocasiones, constituyen un referente inicial de información cuantitativa.

En ausencia de datos, la migración de tránsito podría ser abordada a través de la información de los registros administrativos; en este caso, los generados por la autoridad migratoria, especialmente los que refieren a los extranjeros retenidos por la autoridad migratoria. ${ }^{13}$ Dichos registros contienen, entre otra información, los lugares de ocurrencia del evento, es decir, el lugar geográfico donde se realizó la retención del migrante por agentes del INM. ${ }^{14}$

Comúnmente, las retenciones de migrantes de tránsito no documentados son resultado de operativos itinerantes instalados en diversos lugares dentro de las jurisdicciones de las delegaciones regionales del INM y, en menor medida, se

11 Es ampliamente conocido que los migrantes de tránsito no cuentan, en su mayoría, con documentos que acrediten legal estancia.

12 Debe reconocerse el esfuerzo de la Encuesta sobre Migración en la Frontera Sur de México (EmIF Sur) por captar el fenómeno de la migración de tránsito, cuya metodología está basada en técnicas para medir los desplazamientos de especies migratorias que van de un lugar a otro.

13 En la estadística migratoria generada por el Centro de Estudios Migratorios (CEM), la información aquí utilizada (registros administrativos) se refiere a la suma de los extranjeros que ingresaron en las estaciones migratorias del INM bajo el procedimiento administrativo de aseguramiento y los centroamericanos acogidos a la repatriación voluntaria. Los detalles administrativos de estos procedimientos pueden ser consultados en el Boletín de estadística elaborado por el Centro de Estudios Migratorios.

14 En términos metodológicos, la información se refiere a eventos de retención, en el sentido de que un migrante podría ser detenido en más de ocasión, en sus distintos intentos de cruzar el país, de manera no documentada. 
deben a entregas voluntarias de los migrantes a las estaciones migratorias, esto, sobre todo cuando el curso migratorio se ha complicado ya sea por razones económicas, por extravío o por pérdida del grupo de migrantes de acompañamiento, o bien, por agotamiento físico.

Cabe mencionar que los registros administrativos de extranjeros retenidos dan cuenta de un subconjunto del universo total de la población migrante de tránsito. Desde la perspectiva de Rodríguez et al. (2011), se apunta que las estimaciones de la migración de tránsito por México se conforman por la población asegurada por la autoridad migratoria mexicana, por la población detenida en la frontera sur de Estados Unidos y por aquellos que lograron sortear el camino con éxito y residen ya en el país de destino. Hipotéticamente, los dos primeros subconjuntos, que no lograron su objetivo, se estiman con los registros administrativos de aseguramiento y repatriación.

En este ejercicio se propone trazar las rutas seguidas por los migrantes no documentados de tránsito por México. Para ello, se emplearán los registros administrativos de retenidos por el INM de los años 2010 y 2011. Aquí no se pretende discutir los volúmenes de la migración de tránsito por México; en todo caso, el interés radica en reconstruir las rutas seguidas por el colectivo migrante durante su trayecto o tramo migratorio y vislumbrar algunos cambios en las rutas derivados del incremento de la violencia en algunos municipios de nuestro país que son territorio de cruce casi obligado para este flujo migratorio, en la determinación del trayecto (ruta) seguido. ${ }^{15}$

Potencialidades y limitaciones de los registros administrativos en el estudio de la migración de tránsito por México

Para la construcción de las rutas de tránsito, se sistematizaron los registros administrativos relacionados con la retención de migrantes no documentados, aun cuando eventualmente éstos contienen errores en su captura, derivados de descuidos (voluntarios o no) de los agentes migratorios de las delegaciones regionales del INM. Sin embargo, la información recolectada guarda cierto grado de confiabilidad para la reconstrucción de las rutas para los grupos de migrantes más numerosos, que en el ejercicio propuesto son principalmente los centroamericanos, mismos que históricamente representan el mayor número de retenidos por las autoridades migratorias.

15 La localización de los municipios asociados con violencia se basa en los reportes de la Comisión Nacional de los Derechos Humanos ( $\mathrm{CNDH})$ y notas periodísticas donde se ha identificado actos delictivos contra migrantes.

Perfiles Latinoamericanos | vol. 23, núm. 45, enero-junio de 2015 | Flacso México G. Martínez, S. D. Cobo, J.C. Narváez | Trazando rutas de la migración de tránsito irregular o no documentada 
Los registros administrativos, en términos de representatividad numérica, son diferentes entre las 32 delegaciones regionales. ${ }^{16}$ Por su cercanía geográfica con Centroamérica, los estados del sureste mexicano presentan las proporciones más altas de migrantes de tránsito retenidos por las autoridades migratorias. Entre 2010 y 2011, Chiapas, Tabasco, Oaxaca y Veracruz registraron, en promedio, $70.7 \%$ del total de retenciones de migrantes en tránsito no documentado hacia Estados Unidos.

En un esfuerzo por mostrar la representatividad no sólo porcentual de todos los puntos de retención localizados en las diferentes entidades federativas de México —incluyendo los estados del sur del país que son los que registran la mayor cantidad de migrantes no documentados—, se construyeron regiones geográficas. El análisis de los datos se basa en una regionalización de los puntos de retención derivados de los registros administrativos. En seguida se presentan los criterios y lineamientos seguidos en la propuesta de regionalización.

\section{Construcción de regiones para el trazado de rutas de migración de tránsito}

La metodología propuesta para clasificar los puntos donde ocurrió la retención de los migrantes de tránsito incluye la conformación de cinco zonas geográficas, con las que se agrupa a los lugares representativos por donde los migrantes se desplazan en su tránsito por México. Esto permite conocer eventualmente las rutas de tránsito e identificar posibles cambios y continuidades en las rutas. Entre los criterios para la conformación de cada región se han utilizado la concentración de puntos de retención y su dispersión en cada estado. Otro aspecto importante en la regionalización fue la dimensión territorial de las 32 entidades federativas y la dinámica de los flujos a lo largo del territorio nacional.

Derivado de análisis previos, los estados (Chiapas y Tabasco) que comparten frontera con Guatemala y Belice, tienden a concentrar el mayor número de retenciones de migrantes no documentados en una franja territorial menos extensa que las entidades ubicadas en el centro o en la frontera norte del país. Con la finalidad de reflejar la dinámica de tránsito de migrantes en las entidades federativas, las rutas se presentan por cada una de las cinco regiones geográficas.

A partir de los criterios mencionados con anterioridad, se conformaron cinco regiones: a) región fronteriza del sur: integrada por todos los puntos de retención registrados en una franja promedio de $120 \mathrm{~km}$ a partir de la frontera

16 El InM cuenta con delegaciones regionales en cada uno de las entidades federativas, las cuales se encargan de la aplicación de la normatividad jurídica y de la gestión migratoria en sus demarcaciones administrativas. 140 Perfiles Latinoamericanos | vol. 23, núm. 45, enero-junio de 2015 | FLACso México
G. Martínez, S. D. Cobo, J.C. Narváez | Trazando rutas de la migración de tránsito irregular o no documentada por México | pp. 127-155 
con Guatemala y Belice; en lo que respecta a Quintana Roo y Yucatán, se tomaron territorios completos, ya que si bien en el caso de este último no existe frontera terrestre física, en él llegan a registrarse eventos de retención de migrantes que arribaron vía marítima o aérea. En su conjunto, estos puntos de retención corresponden a la puerta de entrada a México; b) región sureste: compuesta por los puntos de retención situados después de la zona fronteriza sur y que cierran el cinturón de mayor tránsito en el sur de nuestro país; c) región central: que reúne los puntos de retención en los estados centrales del país, donde los entronques y la disponibilidad de distintas vías de comunicación son mayores. Tal vez aquí los migrantes se enfrenten a una de las decisiones más difíciles: optar por caminos más largos con menos alternativas de vías de comunicación pero relativamente más seguros, o caminos más cortos con una mayor red de vías de comunicación, pero con una violencia más palpable y mayor inseguridad; d) región centro-norte: compuesta por todos los puntos de retención situados en los estados norteńos, en municipios que no comparten frontera con Estados Unidos, y que es la más insegura después de las regiones del sur; y e) región fronteriza del norte: compuesta por todos los puntos de retención, prácticamente ya de salida del país y que se ubican en el último tramo antes de intentar cruzar a Estados Unidos.

De todas las regiones geográficas se analizó la dispersión de puntos de retención. Aquellos lugares que sólo mostraban una representación porcentual inferior al 5\% se decidió conjuntarlos con el punto de retención cercano. Esta estrategia, además de disminuir la cantidad de puntos para el mapeo de cada una de las regiones, propicia una mejor visualización de los lugares de tránsito de migrantes. La conformación de regiones y espacios geográficos abona a la mirada integral de la migración de tránsito en el país, de una forma diferente a las antes generadas.

Los puntos de retención marcados en los mapas correspondientes se refieren a las áreas de posible tránsito de los migrantes, ya que, alrededor de un punto georreferenciado, habría caminos alternos o de desvío que los migrantes toman para esquivar los puestos de control migratorio. En realidad, los puntos de retención marcados serían referencias que marcan una probable ruta de tránsito de migrantes.

\section{Análisis de resultados}

Hasta 2010 se percibía que las rutas de la migración de tránsito estaban principalmente sobre el entramado de las vías del ferrocarril y carreteras primarias. Casillas (2007), pionero en el mapeo de las rutas utilizadas por los migrantes 
de tránsito no documentados por México, dejaba constancia entonces de que la ruta de los migrantes estaba fuertemente anclada en las vías y líneas del ferrocarril.

A este primer acercamiento, se fueron sumando en la primera década del siglo XXI distintos factores para el análisis de las rutas de migración de tránsito, como el incremento de los riesgos en la seguridad, principalmente por su vínculo con el crimen organizado. Ello ha propiciado que los migrantes busquen otras alternativas de transportación, lo que ha contribuido a una mayor diversificación de los caminos y rutas por donde ellos transitan. A continuación se presentan los hallazgos del análisis de las cinco regiones de tránsito construidas para explicar los cambios en el camino del migrante hacia Estados Unidos.

\section{Región fronteriza del sur}

Con base en los registros administrativos para 2010, las figuras 1 y 2 muestran los puntos de retención de migrantes de tránsito en la región fronteriza del sur; allí se observa que El Hueyate y Tapachula (Chiapas) son lugares donde ocurrió mayormente la retención de migrantes centroamericanos irregulares. Chiapas fue un significativo punto de entrada de migrantes de tránsito no documentados para ese año.

En 2009, el Informe especial sobre los casos de secuestro en contra de migrantes de la Comisión Nacional de los Derechos Humanos denunció el afianzamiento de la violencia contra los migrantes en los municipios tabasqueños cercanos a la frontera con Guatemala. En este sentido, la evidencia empírica muestra una relativa importancia de Tenosique y El Ceibo (Tabasco) como puntos de retención para ese mismo año. En ambas entidades (Chiapas y Tabasco), los migrantes de tránsito estarían siguiendo las líneas del ferrocarril. Sin embargo, se aprecia menor número de retenciones de migrantes de tránsito por puntos intermedios, donde no se cuenta con líneas de ferrocarril; se trata de zonas de Chiapas.

En contraste, en 2011 se confirmaría una suerte de corrimiento en la ruta de tránsito migratorio. Los principales puntos de retención de migrantes centroamericanos se concentran en Tapachula, El Hueyate y Huehuetán, todos localizados en Chiapas. Estos puntos de retención se sitúan cerca de las vías del tren, en la costa del Pacífico mexicano. Para Tabasco, sólo apareció la zona de Tenosique. Mantienen cierta presencia como puntos de retención los lugares localizados en el centro de Chiapas. Estas zonas implicarían un mayor esfuerzo y tiempo para alcanzar un punto para tomar el tren. Ciertamente, en 2011, la ruta de migración de tránsito se concentra sobre la costa del Pacífico mexicano. 
Figura 1. Principales puntos de retención de migrantes centroamericanos de tránsito no documentado, región fronteriza del sur, 2010

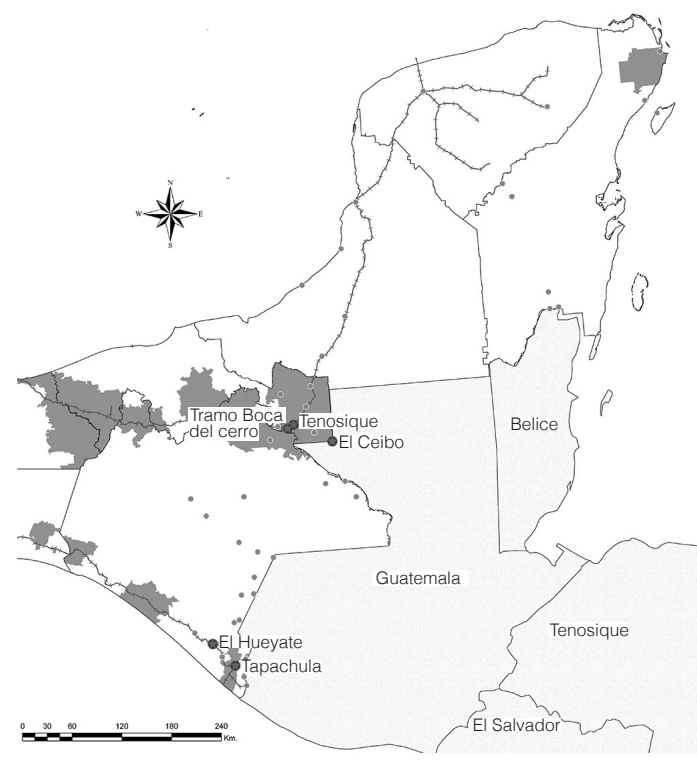

\begin{tabular}{lc} 
Principales puntos de retención & 2010 (\%) \\
\hline El Hueyate, Chis. & 29.5 \\
Tapachula, Chis. & 15.1 \\
Tenosique, Tab. & 13.9 \\
El Ceibo, Tab. & 8.1 \\
Tramo Boca del Cerro, Tab. & 5.0 \\
Comitán, Chis. & 4.0 \\
Tramo Trinitaria, Chis. & 3.4 \\
El Guasiván, Tab. & 3.0 \\
Chancalá-Palenque, Chis. & 2.5 \\
G. Méndez Magaña, Tab. & 2.2 \\
San Cristóbal, Chis. & 1.7 \\
La Última Lucha, Tab. & 1.3 \\
San Gregorio Chamic, Chis. & 1.3 \\
El Águila, Tab. & 1.2 \\
Cd. Cuauhtémoc, Chis. & 1.0 \\
Otros & 6.8 \\
\hline Total & 100 \\
& \\
O Principales puntos de retención & \\
región fronteriza del sur, 2010 & \\
Puntos de retención 2010 & \\
\hline Municipios de riesgo para migrantes, & \\
\end{tabular}

Fuente: Elaboración propia con base en registros administrativos del INM.

Total nacional (2010) 60,220

Figura 2. Principales puntos de retención de migrantes centroamericanos de tránsito no documentado, región fronteriza del sur, 2011

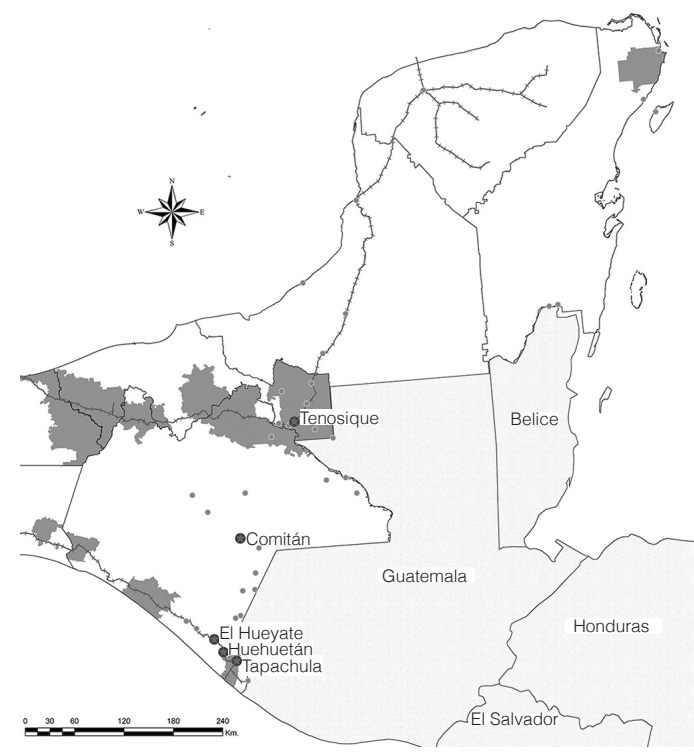

\begin{tabular}{lc} 
Principales puntos de retención & 2011(\%) \\
\hline Tapachula, Chis. & 29.9 \\
El Hueyate, Chis. & 19.4 \\
Huehuetán, Chis. & 7.8 \\
Comitán, Chis. & 6.1 \\
Tenosique, Tab. & 5.7 \\
Chancalá-Palenque, Tab. & 5.3 \\
Tramo Trinitaria, Chis. & 4.8 \\
Cd. Cuauhtémoc, Chis. & 4.1 \\
Tramo Metapa-Cd. Hidalgo, Chis. & 2.1 \\
San Gregorio Chamic, Chis. & 2.0 \\
La Última Lucha, Tab. & 1.5 \\
El Ceibo, Tab. & 1.4 \\
G. Méndez Magaña, Tab. & 1.2 \\
Tramo Boca del Cerro, Tab. & 1.1 \\
Cd. Hidalgo, Chis. & 1.1 \\
Otros & 6.4 \\
\hline Total & 100 \\
O Principales puntos de retención & \\
- región fronteriza del sur, 2011 & \\
Puntos de retención 2011 & \\
\hline &
\end{tabular}

Fuente: Elaboración propia con base en registros administrativos del INM.

Total nacional (2011) 59,878

Perfiles Latinoamericanos | vol. 23, núm. 45, enero-junio de 2015 | Flacso México G. Martínez, S. D. Cobo, J.C. Narváez | Trazando rutas de la migración de tránsito irregular o no documentada 


\section{Región sureste}

Una vez que se ha logrado cruzar la región de la frontera sur, el contingente de migrantes continúa su camino por la región sureste, constituida por municipios y zonas de Chiapas, Tabasco, Veracruz y Oaxaca. Entre 2007 y 2009, los medios de comunicación señalaban que el flujo de centroamericanos transitaba por Chontalpa, Macuspana y Playas de Catazajá (Tabasco), Acayucan (Veracruz), San Pedro Tapanatepec y La Ventosa (Oaxaca).

Los datos derivados de los registros administrativos de 2010 muestran tal tendencia, pese que se trata de lugares distantes. En realidad, podemos identificar tres rutas de tránsito; una que sigue la costa del Pacífico, otra que bordea la costa del Golfo de México y una que recorre el centro de Chiapas. En este sentido, se destaca Tuxtla Gutiérrez, capital del estado de Chiapas, como principal lugar de tránsito de migrantes centroamericanos. Este resultado es relevante porque confirmaría el argumento de que aparece una ruta de tránsito que no necesariamente sigue las líneas ferroviarias.

Figura 3. Principales puntos de retención de migrantes centroamericanos de tránsito no documentado, región sureste, 2010

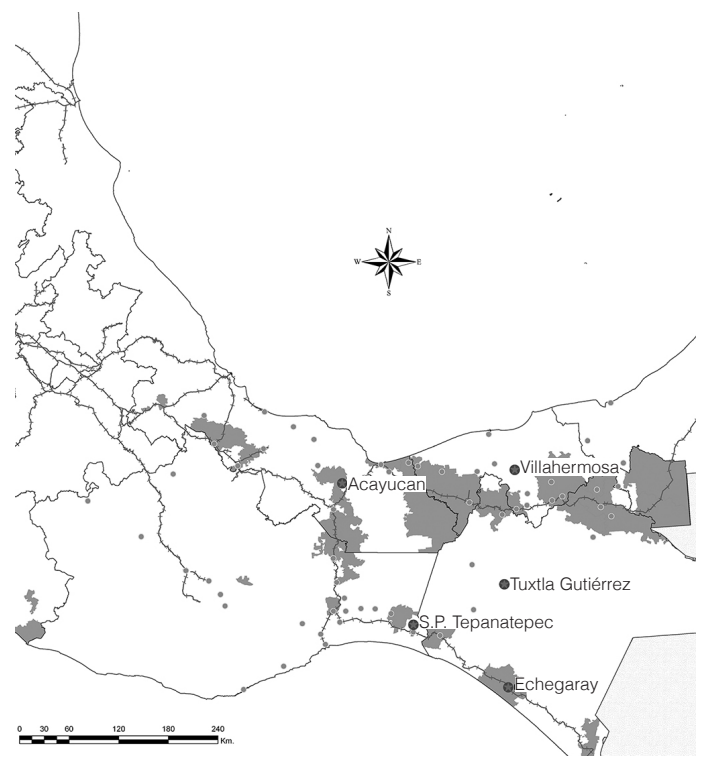

Fuente: Elaboración propia con base en registros administrativos del INM.

\begin{tabular}{lc} 
Principales puntos de retención & 2010 (\%) \\
\hline San Pedro Tapanatepec, Oax. & 8.21 \\
Echegaray, Chis. & 7.95 \\
Acayucan, Ver. & 7.88 \\
Villahermosa, Tab. & 5.87 \\
Tuxtla Gutiérrez, Chis. & 5.64 \\
Arriaga, Chis. & 5.46 \\
La Pochota, Chis. & 5.37 \\
Chontalpa, Tab. & 4.09 \\
La Ventosa, Oax. & 3.97 \\
Playas de Catazajá, Chis. & 3.63 \\
Tramo Escárcega-Villahermosa, Tab. & 3.51 \\
Chahuites, Oax. & 3.42 \\
Tramo Ocozocoautla-Las & \\
Choapas, Chis. & 2.85 \\
Coatzacoalcos, Ver. & 2.70 \\
Cárdenas, Tab. & 2.62 \\
Otros & 26.9 \\
\hline Total & 100 \\
& \\
- Principales puntos de retención & \\
Total nacional (2010) 60,220 & \\
\hline Puntos de retención 2010 & \\
\hline & \\
\hline & \\
\hline &
\end{tabular}

Total nacional (2010) 60,220 
Figura 4. Principales puntos de retención de migrantes centroamericanos de tránsito no documentado, región sureste, 2011

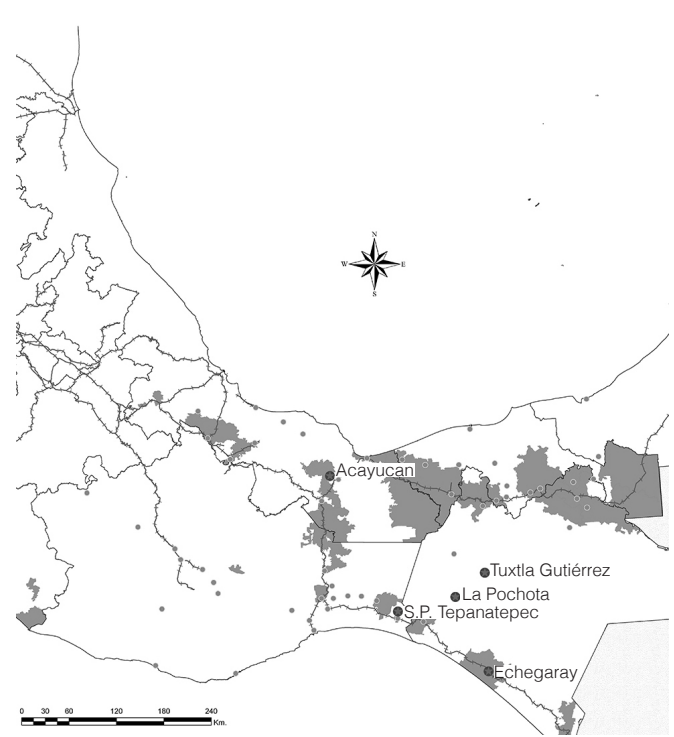

Fuente: Elaboración propia con base en registros administrativos del INM.

\begin{tabular}{lc} 
Principales puntos de retención & 2011(\%) \\
\hline Tuxtla Gutiérrez, Chis. & 9.84 \\
Echegaray, Chis. & 9.59 \\
Acayucan, Ver. & 9.03 \\
La Pochota, Chis. & 7.04 \\
San Pedro Tapanatepec, Oax. & 5.66 \\
Villahermosa, Tab. & 5.08 \\
La Ventosa, Oax. & 4.56 \\
Playas de Catazajá, Chis. & 4.19 \\
Palenque, Chis. & 3.84 \\
Tramo Ocozocoautla-Las Choapas, & \\
Chis. & 3.65 \\
Arriaga, Chis. & 3.42 \\
Tramo Escárcega-Villahermosa, Tab. & 2.54 \\
Tramo Ocotepec-Huitzo, Mor. & 2.30 \\
Oaxaca, Oax. & 2.26 \\
La Venta, Tab. & 2.22 \\
Otros & 24.8 \\
\hline Total & 100 \\
& \\
- Principales puntos de retención & \\
región sureste, 2011 & \\
Total nantos de retención 2011 & \\
4- Vunicipios de riesgo para migrantes, & \\
\hline & \\
\hline
\end{tabular}

Se subrayan los puntos de Echegaray, Chiapas y San Pedro Tapanatepec, Oaxaca, casi en línea recta, como zonas de posible tránsito de migrantes no documentados. Otros puntos importantes se localizaron en Villahermosa, Tabasco y Acayucan, Veracruz.

Para 2011, se observa que los puntos de retención se concentran en zonas de Chiapas (Echagaray) y San Pedro Tapanatepec, Oaxaca. Asimismo, se confirma la preponderancia de Tuxtla Gutiérrez, como espacio de tránsito de migrantes centroamericanos. Se subraya la presencia de otro punto de retención (La Pochota) en el centro de Chiapas. Es posible que la ruta del Golfo de México, con cierta importancia en el año previo, pierda relevancia, como consecuencia del recrudecimiento de la violencia contra migrantes en zonas de Tabasco.

\section{Región central}

Para 2010, los puntos de mayor retención en la región se presentaron en Apizaco, Tlaxcala y Toluca, Estado de México, seguidos por San Luis Potosí, San Luis Potosí. En orden de importancia, aparecen también puntos en Tepeapulco, 
Hidalgo e Iztapalapa (7.9\%), en la capital del país. Posiblemente, la ruta de tránsito de los migrantes sea casi en línea recta, pero siguiendo las líneas de tren. Esta idea es apoyada por el hecho de que no aparecen, de manera significativa, puntos de retención en zonas costeras en los estados de Guerrero, Michoacán y Veracruz.

Figura 5. Principales puntos de retención de migrantes centroamericanos de tránsito no documentado, región central, 2010

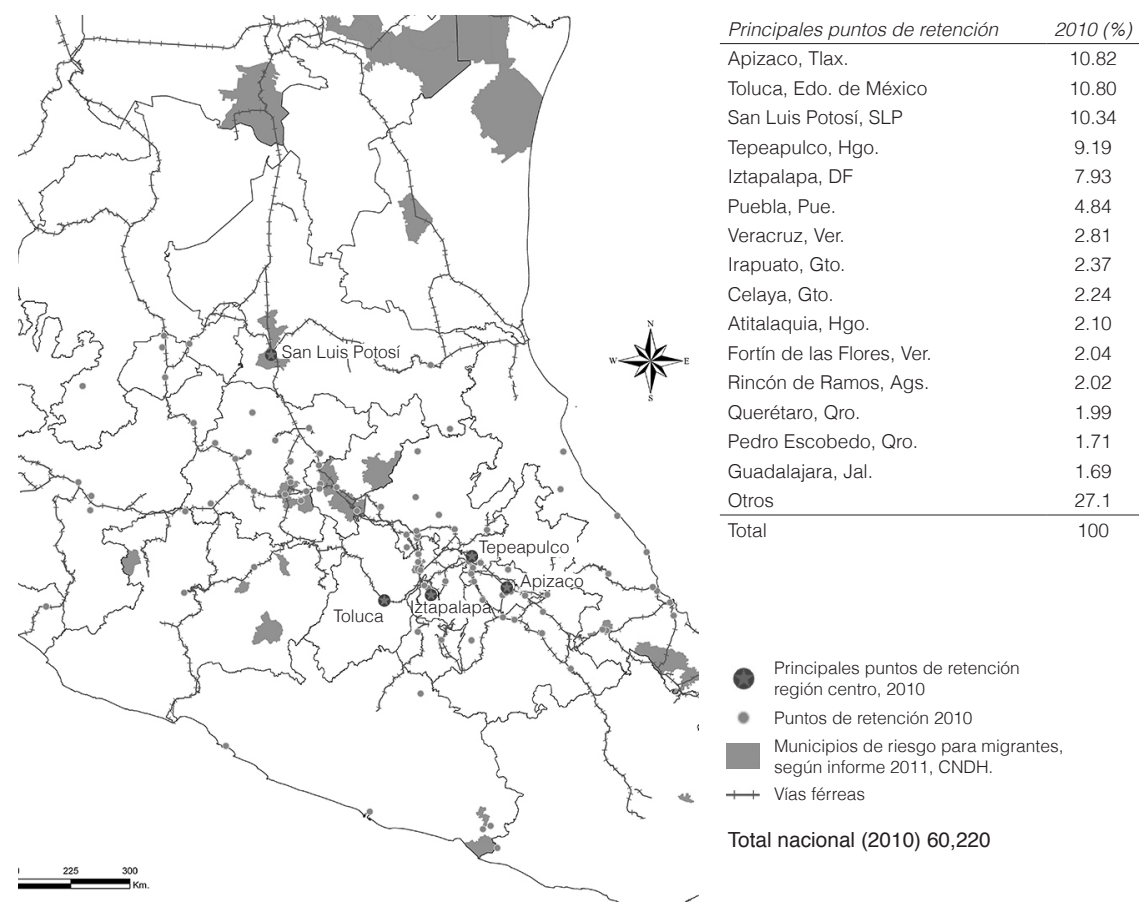

Fuente: Elaboración propia con base en registros administrativos del INM

Para 2011, los puntos de retención se dieron en San Luis Potosí, San Luis Potosí, Toluca, Estado de México y Tepeapulco, Hidalgo. Destaca también Iztapalapa, en el Distrito Federal. Entre los periodos observados, no se distinguen cambios drásticos. En realidad, los migrantes centroamericanos intentaron transitar por rutas cercanas a las vías del ferrocarril. En la región central, los migrantes de tránsito tienden a converger en determinadas zonas, para después tomar distintas rutas hacia el norte. 
Figura 6. Principales puntos de retención de migrantes centroamericanos de tránsito no documentado, región central, 2011

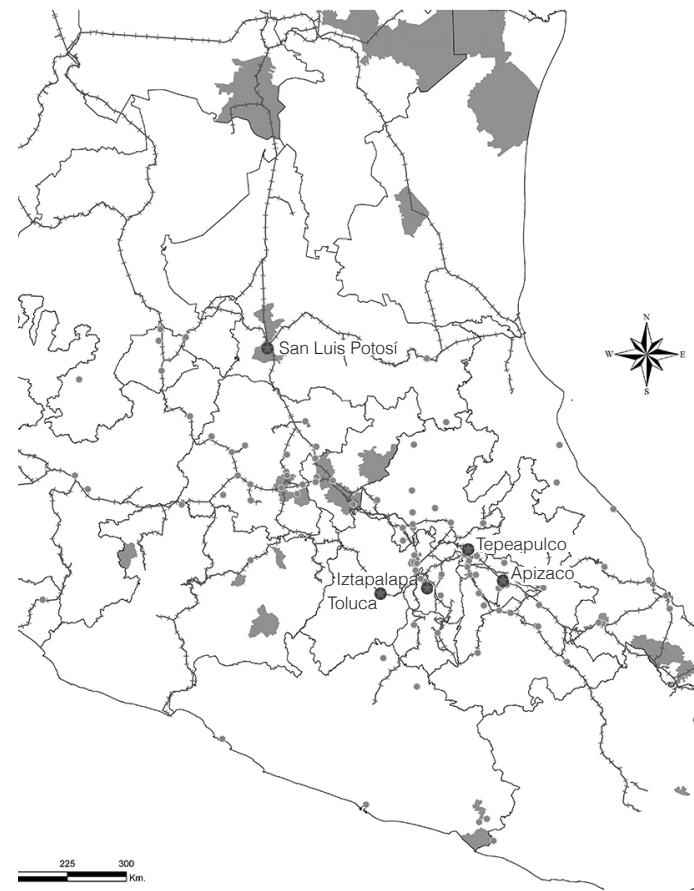

\begin{tabular}{lc} 
Principales puntos de retención & $2011(\%)$ \\
\hline San Luis Potosí, SLP & 21.31 \\
Toluca, Edo. de México & 14.32 \\
Tepeapulco, Hgo. & 12.45 \\
Iztapalapa, DF & 8.43 \\
Apizaco, Tlax. & 4.56 \\
Veracruz, Ver. & 3.49 \\
Querétaro, Qro. & 2.65 \\
Puebla, Pue. & 2.41 \\
Celaya, Gto. & 2.11 \\
Pedro Escobedo, Qro. & 1.91 \\
Palmillas, Qro. & 1.87 \\
San Miguel de Allende, Gto. & 1.47 \\
La Antigua, Ver. & 1.41 \\
Irapuato, Gto. & 1.38 \\
Cto. Term. de autobuses, DF & 1.11 \\
Otros & 19.1 \\
\hline Total & 100
\end{tabular}

Fuente: Elaboración propia con base en registros administrativos del INM.

\section{Región centro-norte}

En 2010, los puntos de retención de migrantes de tránsito se concentraron en Saltillo, Coahuila, Mazatlán, Sinaloa y, en menor medida, en Chihuahua, Chihuahua. Se subraya la aparición de puntos en Cadereyta, Nuevo León y Culiacán, Sinaloa. En esta región se aprecia, de alguna manera, tres rutas. La primera en el centro del país hasta Chihuahua; una segunda que continuaría su viaje por el noroeste, hasta Cadereyta y, finalmente, una ruta que bordea la costa del Pacífico, por Mazatlán y Culiacán, con el propósito de llegar a la frontera con California y Arizona (Estados Unidos). Como se observa en los mapas, la ruta de tránsito en la región centro-norte se vincula fuertemente a las líneas del ferrocarril.

Los puntos de mayor retención de migrantes de tránsito para 2011, ahora se centran en Saltillo, Mazatlán, y Cadereyta y Monterrey, en Nuevo León. 
Estos dos últimos puntos, geográficamente cercanos, apuntarían a una ruta que posiblemente pretendan seguir los migrantes de tránsito para salir de México, por alguna zona de Tamaulipas. Esta situación es preocupante, sobre todo si continúa dicha tendencia en el corto y mediano plazos, porque se trataría de una región caracterizada por la presencia de grupos del crimen organizado y de tráfico de personas. Los datos confirman que la zona noroeste de México es una región de tránsito de centroamericanos a Estados Unidos.

Figura 7. Principales puntos de retención de migrantes centroamericanos de tránsito no documentado, región centro-norte, 2010

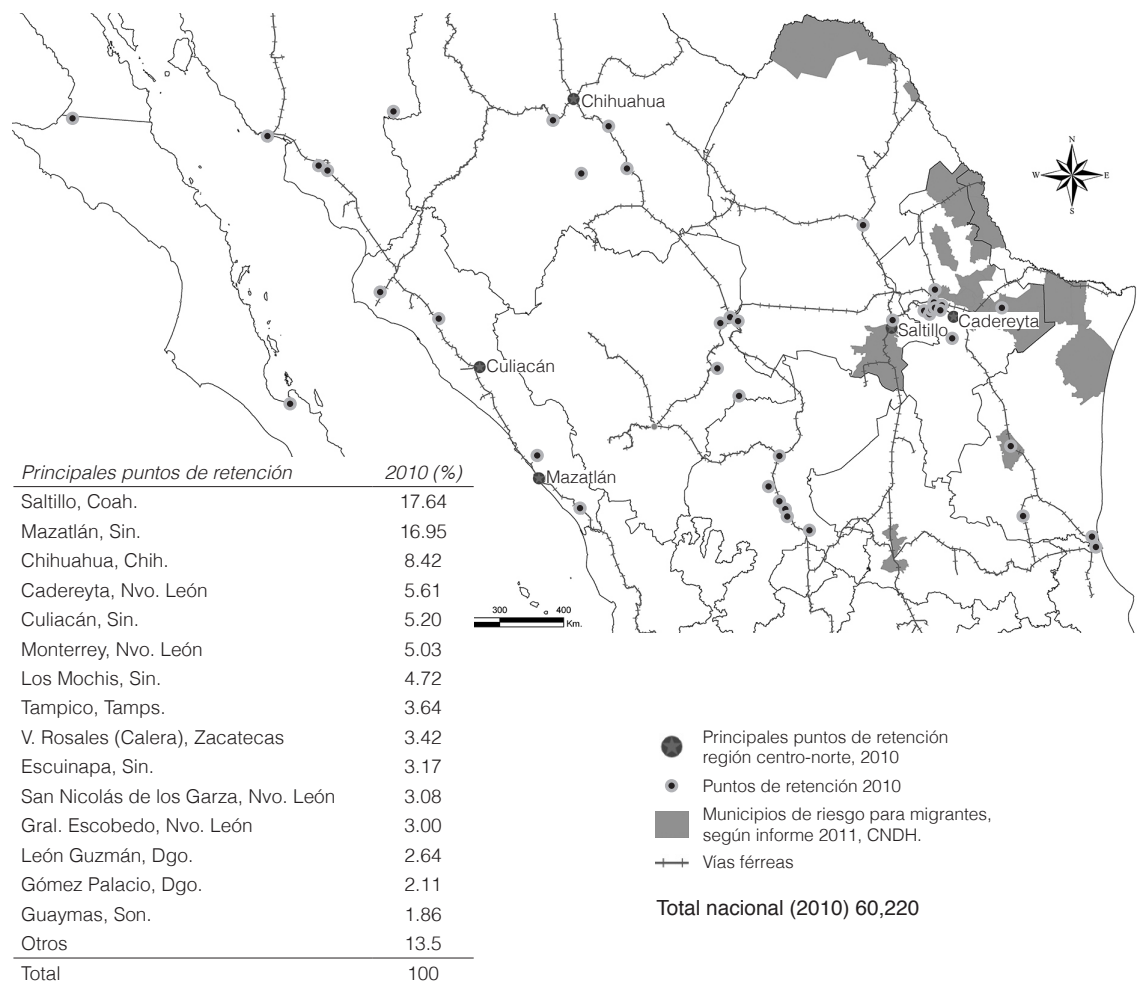

Fuente: Elaboración propia con base en registros administrativos del INM.

Se llama la atención acerca de la presencia de puntos de retención de migrantes de tránsito en la costa del Pacífico; específicamente, en los puntos cercanos al puerto de Mazatlán. La ruta migratoria hacia el norte, principalmente hacia 
Sonora o Baja California, mantiene su vigencia para el tránsito de migrantes centroamericanos.

Figura 8. Principales puntos de retención de migrantes centroamericanos de tránsito no documentado, región centro-norte, 2011

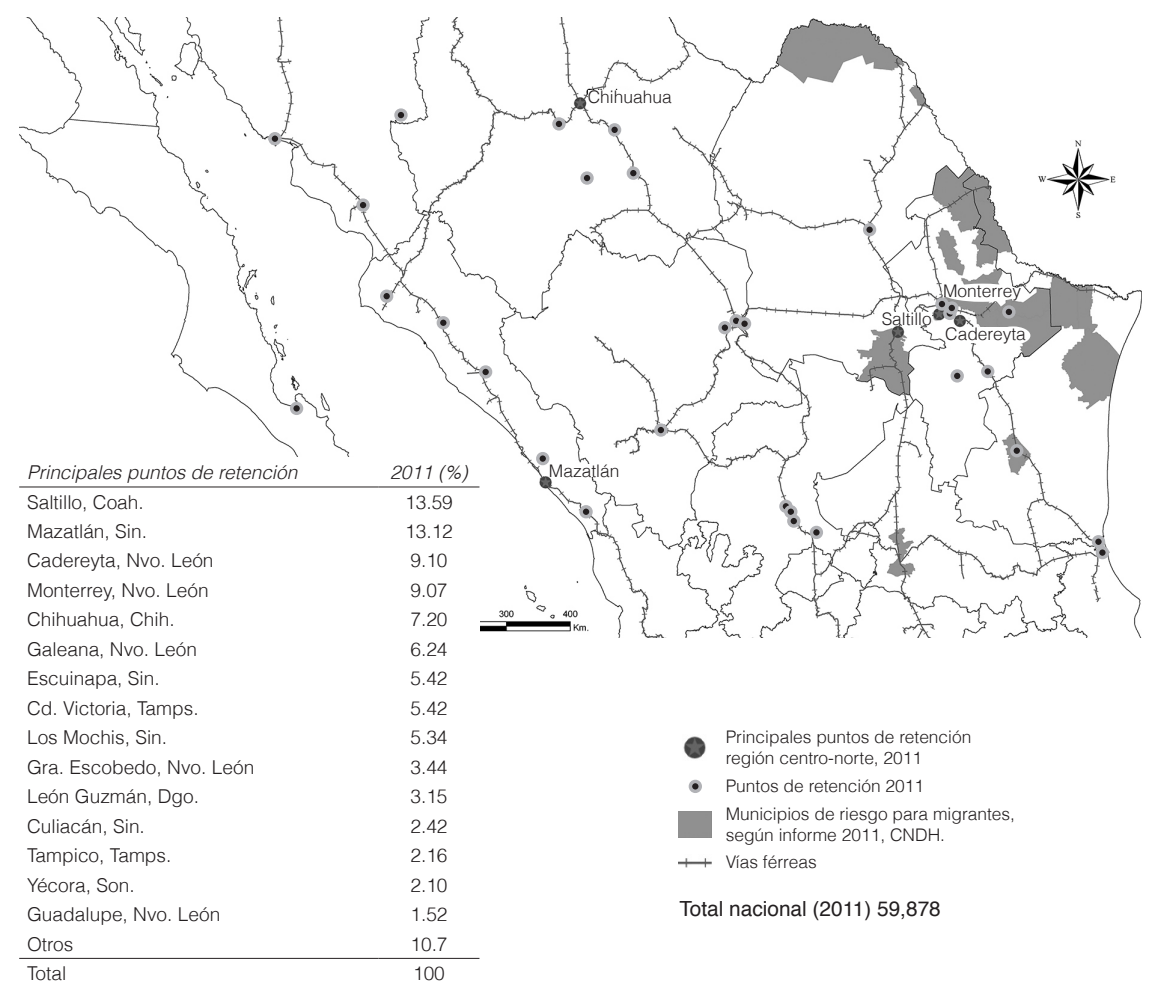

Fuente: Elaboración propia con base en registros administrativos del INM.

\section{Región fronteriza del norte}

En la región fronteriza del norte como puntos de retención de migrantes de tránsito destacaron: Hermosillo (Sonora), Nuevo Laredo (Tamaulipas), Janos y Ciudad Juárez (Chihuahua) y Tijuana (Baja California). Este dato abona a la idea de que las rutas migratorias de tránsito, en sus puntos de salida a Estados Unidos, son aún dispersas. Tal vez la elección de la ruta de tránsito por México tenga su momento de decisión más difícil para los migrantes en 
la región fronteriza, no sólo por los problemas de inseguridad de las zonas, sino también por el destino final en Estados Unidos. En términos generales, el mapa muestra que el flujo migratorio de tránsito tomaría, posiblemente, una salida por Baja California, Sonora o Tamaulipas.

Figura 9. Principales puntos de retención de migrantes centroamericanos de tránsito no documentado, región fronteriza del norte, 2010

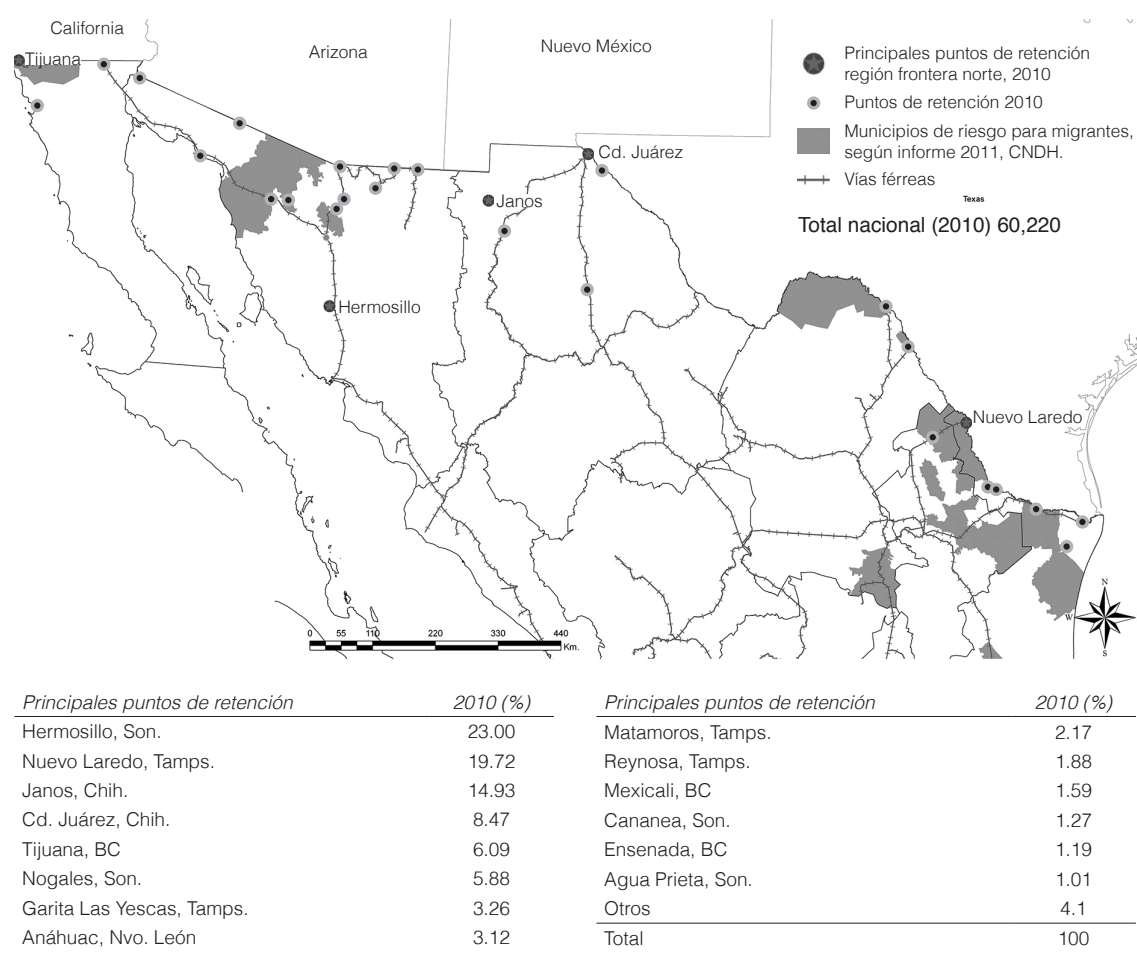

Piedras Negras, Coah.

2.30

Fuente: Elaboración propia con base en registros administrativos del INM.

En 2011, los puntos de retención prácticamente se mantienen sin modificaciones, con la excepción de la incorporación de Reynosa, Tamaulipas. En esta región, la ruta de tránsito se concentró fuertemente en la frontera del noroeste de México, de tal suerte que los migrantes centroamericanos estarían intentando ingresar a Estado Unidos por algún punto de Texas. La comparación de los listados de puntos de retención permite observar una 
redistribución a lo largo de las rutas, puntos históricamente tradicionales se desdibujan del mapa en 2010, pero, para 2011, muestran un resurgimiento, lo cual puede hablar del reacomodo de las rutas de tránsito de cara al cruce final hacia Estados Unidos.

Figura 10. Principales puntos de retención de migrantes centroamericanos de tránsito no documentado, región fronteriza del norte, 2011

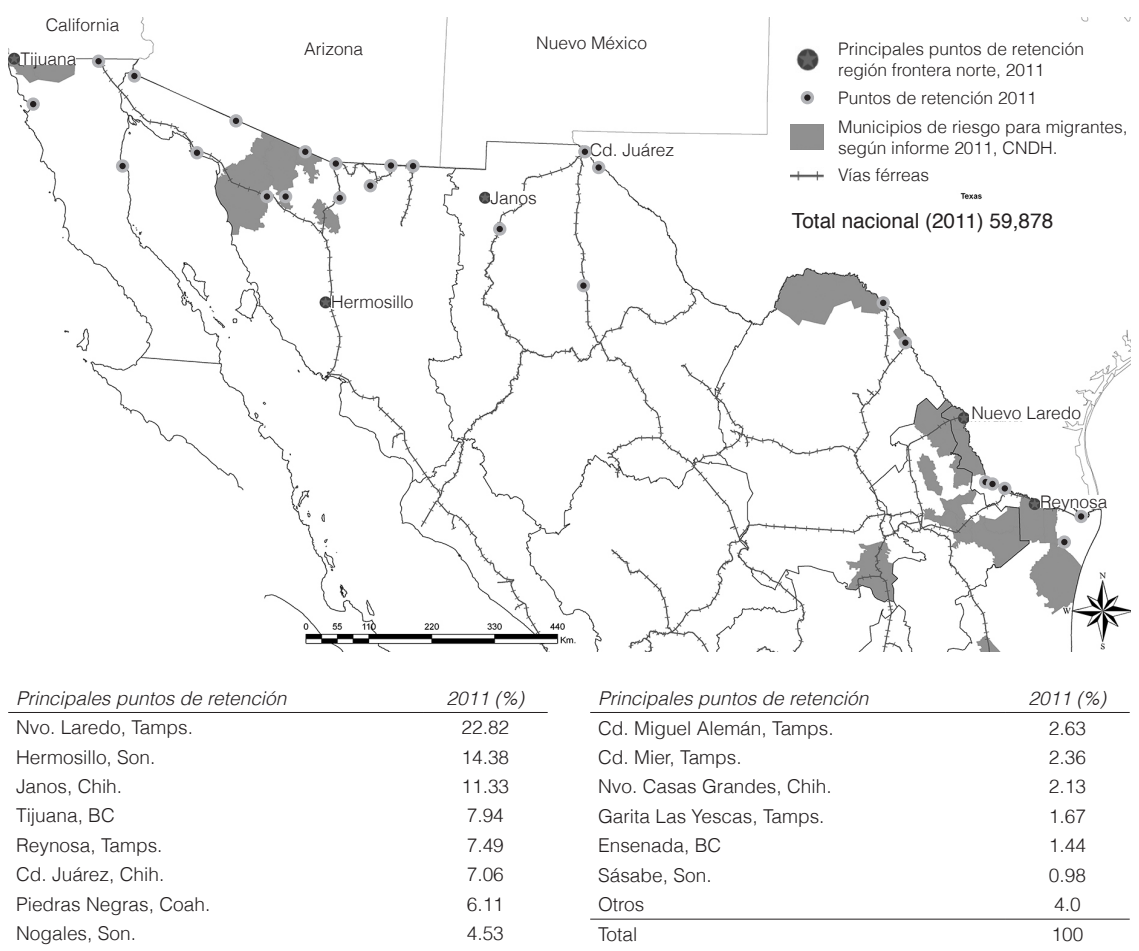

Mexicali, BC

3.09

Fuente: Elaboración propia con base en registros administrativos del INM.

\section{Conclusiones}

La ruta del tren, las vías carreteras y los caminos de extravío que cruzan México de sur a norte son las estrategias que van intercalando los migrantes en tránsito no documentados para llegar desde la frontera sur de México hasta Estados Unidos. 
El estudio de las rutas migratorias de tránsito es una tarea compleja, dada la invisibilidad de los propios migrantes; acercarse a ellos es sumamente difícil. Los medios de comunicación han sido fuente de información sistemática, pues a través de sus notas se ha podido reunir información en torno a los caminos y las trayectorias de la migración de tránsito no documentada. En contraparte, los censos de población o las encuestas en hogares en México (herramientas tradicionales para medir los flujos migratorios) no posibilitan aproximaciones cuantitativas de la migración de tránsito, ya que, por obvias razones, los migrantes en su cruce por el país no establecen un domicilio permanente.

En esta lógica de argumentación, los registros administrativos de la autoridad migratoria mexicana - pese a sus limitaciones - permiten una propuesta de análisis de las rutas de los migrantes no documentados en México. La apuesta metodológica radicó, precisamente, en la revisión de los registros del INM relacionados con los eventos de retención de migrantes no documentados, para delinear las posibles rutas de tránsito hacia Estados Unidos. Este trabajo de investigación procuró la presentación de los puntos de retención derivados de los propios registros administrativos por medio de un análisis por regiones geográficas del país.

De cara a los cambios sociales y políticos sobre los que se ha desarrollado la migración de tránsito en los últimos años, fenómeno en el que, además de las medidas de control fronterizo para ingresar tanto a México como a Estados Unidos, la incorporación del crimen organizado y la consolidación de la industria del tráfico de migrantes, así como la creciente violencia en el país dirigida en contra de los migrantes, han generado cambios en la circularidad de los flujos migratorios, y en las vías y regiones de traslado tradicionales. En este contexto, este trabajo de investigación mapeó los puntos de retención de migrantes no documentados, los cuales posiblemente dan cuenta de las rutas de traslado de los centroamericanos no documentados en tránsito por México, entre 2010 y 2011.

En general, se observa una diversificación de los puntos de retención en la región desde la frontera sur; por ejemplo, se aprecia la consolidación de una posible ruta que corre por el centro de Chiapas. Asimismo, algunos cambios en los puntos de ingreso a México, en el periodo 2010-2011, muestran cierta modificación en cuanto a que los migrantes que ingresaban por Tabasco, debido a las afectaciones a las vías de comunicación provocadas por los fenómenos naturales, volvieron a los puntos tradicionales de Chiapas, dada la presencia y el incremento de la violencia hacia los migrantes en esta zona.

Los migrantes de tránsito convergen en puntos nodales en la región sureste, no necesariamente asociados al ferrocarril. Los migrantes de tránsito también se mueven por diversas rutas por la costa del Golfo de México, sobre todo en los tiempos más recientes. La rutas de los migrantes por el centro del país permanecen, prácticamente, sin mayores cambios. 
Los puntos de retención en la zona centro-norte, en realidad se encuentran vinculados con el entramado de las vías de ferrocarril. Los datos sugieren que los migrantes siguen una ruta costera por Sinaloa y, dos más, hacia Chihuahua y al noroeste de México. Finalmente, los puntos posibles de salida de México se presentan sin mayores modificaciones. De hecho, los registros de eventos de retención muestran una consolidación de la ruta que atraviesa Nuevo León y Tamaulipas. Es probable que los migrantes de tránsito estén buscando cruzar a Estados Unidos por algún punto de Texas.

Los resultados mostrados en este ejercicio analítico abren nuevas vetas de investigación que buscarían contribuir a la comprensión de las rutas de los migrantes de tránsito. En este sentido, por ejemplo, supondríamos que los migrantes muestran diferencias en las rutas que siguen en función de las redes de apoyo que establecen por país de origen; así como también, dada la inseguridad en ciertas zonas y regiones de México, las rutas de tránsito mostrarían diferencias según sexo y edad del migrante.

\section{Referencias}

Ángeles Cruz, Hugo, 2003, "La migración internacional a través de la frontera Sur", Ecofronteras, núm. 19, agosto, pp. 5-8.

Ángeles Cruz, Hugo, 2001, “Los flujos migratorios laborales en la frontera sur de México”, en Población y desarrollo sustentable, Guanajuato, Consejo Estatal de Población del Estado de Guanajuato, pp. 103-106.

Anguiano, María Eugenia, y Rodolfo Corona (coords.), 2009, Flujos migratorios en la frontera Guatemala-México, México, El Colegio de la Frontera Norte/Instituto Nacional de Migración/DGE Editores.

Benítez Manaut, Raúl, 2011, "México, Centroamérica y Estados Unidos: migración y seguridad", en Natalia Armijo (edit.), Migración y seguridad: nuevo desafío en México, México, Colectivo de Análisis de la Seguridad con Democracia, pp. 179-192.

Casillas, Rodolfo, 2010, "Masacre de transmigrantes", Foreign Affairs Latinoamérica, vol. 10, núm. 4, pp. 52-59.

Casillas, Rodolfo, 2007, Una vida discreta y fugaz. Los centroamericanos transmigrantes en México, México, Comisión Nacional de los Derechos Humanos/Organización Internacional para las Migraciones.

Perfiles Latinoamericanos | vol. 23, núm. 45, enero-junio de 2015 | Flacso México

G. Martínez, S. D. Cobo, J.C. Narváez | Trazando rutas de la migración de tránsito irregular o no documentada 
Castillo, Manuel Ángel, 2008, "La frontera México-Guatemala: un entorno de asimetrías, desigualdades sociales y movilidad poblacional. Proyecto: Desarrollo de propuestas de política pública en asuntos de migración", Cambiando perspectivas: de la gestión de flujos hacia la construcción de politicas de migración con enfoque de desarrollo, México, Sin Fronteras/IAp/Universidad Autónoma de Zacatecas/Incide Social/Miguel Ángel Porrúa, pp.58-93.

Castillo, Manuel Ángel, y Mónica Toussaint, 2010, “Seguridad y migración en la frontera sur”, en Arturo Alvarado y Mónica Serrano (coords.), Seguridad nacional y seguridad interior, México, El Colegio de México, pp. 269-300.

Comisión Nacional de los Derechos Humanos, 2009, Informe especial sobre los casos de secuestro en contra de migrantes de la $C N D H$, México.

Düvell, Franck, 2006, "Questioning conventional migration concepts: the case of transit migration", documento presentado en el taller Gaps and Blindspots of Migration Research, Budapest, Central European University.

El Colegio de la Frontera Norte, Secretaría del Trabajo y Previsión Social, Consejo Nacional de Población, Instituto Nacional de Migración, Secretaría de Relaciones Exteriores, 2011, Encuesta sobre Migración en la Frontera Sur de México, México

García, María del Carmen, y María Tarrío, 2008, "Migración irregular centroamericana. Las tensiones entre derechos humanos, ley y justicia”, en Daniel Villafuerte y María del Carmen García (coords.), Migraciones en el sur de México y Centroamérica, México, H. Cámara de Diputados, Lx Legislatura/Universidad de Ciencias y Artes de Chiapas/Miguel Ángel Porrúa, pp. 123-170.

Herrera-Lasso, Luis, y Juan Artola, 2011, "Migración y seguridad: dilemas e interrogantes", en Natalia Armijo (edit.), Migración y seguridad: nuevo desafio en México, México, Colectivo de Análisis de la Seguridad con Democracia, pp. 11-34.

Jaúregui, José Alfredo, y María de Jesús Ávila, 2009, "México: país de tránsito para migrantes guatemaltecos camino a Estados Unidos”, en María Eugenia Anguiano y Rodolfo Corona (coords.), Flujos migratorios en la frontera Guatemala-México, México, El Colegio de la Frontera Norte/Instituto Nacional de Migración/Dge Editores, pp. 247-280.

Kauffer, Michelle, 2003, "Entre peligros y polleros: la travesía de los indocumentados centroamericanos”, Ecofronteras, núm. 19, agosto, pp. 9-11.

Narváez Gutiérrez, Juan Carlos, 2007, Ruta transnacional: a San Salvador por Los Ángeles. Espacios de interacción juvenil en un contexto migratorio, Universidad Autónoma de Zacatecas/Instituto Mexicano de la Juventud/Miguel Ángel Porrúa, México. 
Narváez Gutiérrez, Juan Carlos, y Nina Frías Valle, 2011, "Enfoques teórico-metodológicos y aproximaciones a las fuentes cualitativas y cuantitativas para el estudio de la migración de tránsito por México", ponencia presentada en el Séptimo Congreso Nacional de Investigación Social de la Universidad Autónoma del Estado de Hidalgo, 24 de octubre, Pachuca, México.

Pérez García, Nancy, 2008, "Seguridad nacional vs. seguridad humana: su impacto en la migración”, en Sin Fronteras (edits.), Cambiando perspectivas. De la gestión de flujos hacia la construcción de politicas de migración con enfoque de desarrollo, México, UAz/Sin Fronteras/ INCIDE Social/Miguel Ángel Porrúa, pp. 94-145.

Rodríguez Chávez, Ernesto, Salvador Berumen Sandoval, y Luis Felipe Ramos, 2011, "Migración centroamericana de tránsito irregular por México. Estimaciones y características generales", Apuntes sobre migración, núm. 01, julio, México, Centro de Estudios Migratorio del INM.

Rojas Weisner, Martha, 2006, "Migración en la frontera sur de México: mujeres hacia y a través del Soconusco", en Las mujeres en la migración. Testimonios, realidades y denuncias, Mexicali, Baja California, Albergue del Desierto, pp. 41-114.

Rojas Weisner, Martha, 2003, "La frontera de Chiapas con Guatemala como región de destino de migrantes internacionales”, Ecofronteras, núm. 19, San Cristóbal de las Casas, Chiapas, El Colegio de la Frontera Sur, México, pp. 15-17.

Ruiz Majurro, Olivia, 2001, "Los riesgos de cruzar. La migración centroamericana en la frontera México-Guatemala”, Revista Frontera Norte, vol. 13, enero-junio, núm. 25, pp. 7-33.

Singer, Paul, 1998, Economía política de la urbanización, México, Editorial Siglo XXI.

Stumpf, Juliet P., 2006, “The Crimmigration Crisis: Immigrants, Crime, and Sovereign Power”, American University Law Review, vol. 56, pp. 367-419.

Unidad de Política Migratoria, SEGOB, 2005-2011, Boletín estadístico mensual, México.

Recibido el 14 de febrero de 2013. Aceptado el 22 de septiembre de 2014. 
